\title{
Case studies in brain dosimetry for internal emitters: Is more detail needed for epidemiology?
}

\author{
Richard W. Leggett ${ }^{1, *}$, Sergei Y. Tolmachev ${ }^{2}$, John D. Boice, $\mathrm{Jr}^{3}$ \\ ${ }^{1}$ Oak Ridge National Laboratory, Oak Ridge, TN 37831, USA \\ ${ }^{2}$ U.S. Transuranium and Uranium Registries, College of Pharmacy, Washington State University, \\ 1845 Terminal Drive, Suite 201, Richland, WA 99354, USA \\ ${ }^{3}$ National Council on Radiation Protection and Measurements, 7910 Woodmont Ave, Ste 400, \\ Bethesda, MD 20814, USA
}

\section{Abstract}

Element-specific biokinetic models are used to reconstruct doses to systemic tissues from internal emitters. These models typically depict explicitly only those tissues that tend to dominate the systemic behaviour of the element over time. The remaining tissues are aggregated into a pool called Other tissue in which activity is assumed to be uniformly distributed. Explicitly identified tissues usually consist of some subset of the tissues liver, kidneys, bone, bone marrow, gonads, thyroid, spleen, and skin.

The brain is included explicitly in systemic biokinetic models for a few elements but typically is addressed as an implicit mass fraction of Other tissue. There is increasing interest in the potential adverse effects of internal emitters, particularly alpha emitters, on the brain as limited analogues for galactic cosmic ray (GCR) exposures during space travel and for possible assessment of radiogenic effects on brain in nuclear medicine patients and radiation workers. For National Aeronautics and Space Administration, the need is to provide protection against in-flight behavioural and cognitive impairments from GCRs on the central nervous system, as well as long-term dementia and motor neuron diseases $[1,2]$. The Million Worker Study (MWS), underway in the US, is estimating brain doses from exposure to radionuclides and evaluating dementia, Alzheimer's disease, Parkinson's disease, and motor neuron disease as possible adverse outcomes of combined high- and low-LET exposures to brain tissue [2,3].

This paper summarizes an assessment of potential improvements in brain dosimetry for internal emitters from explicit modelling of brain kinetics in place of treating the brain as an implicit mass fraction of Other tissue. Comparisons are made of dose coefficients for selected radionuclides based on alternate versions of the systemic biokinetic model for each radionuclide, differing only in the handling of brain tissue.

As an illustration, the systemic model for plutonium $(\mathrm{Pu})$ used in the MWS [4] includes brain implicitly in Other tissue. The most relevant brain-specific data available for modelling brain kinetics of Pu appears to be autopsy data for Pu workers. Since 1968, the U.S. Transuranium and Uranium Registries (USTUR) has studied the biokinetics (deposition, translocation, retention, and excretion) and tissue dosimetry of actinide elements in occupationally exposed individuals (volunteer Registrants) [5]. The USTUR holds data on work history, radiation exposure and bioassay measurements, and medical records from more than 400 former nuclear workers, mainly exposed to ${ }^{239} \mathrm{Pu}$. The activity of ${ }^{239} \mathrm{Pu}$ in brain has been measured post mortem in several individuals. As a central estimate (either mean or median) for these individuals, the brain contains $\sim 0.2 \%$ as much ${ }^{239} \mathrm{Pu}$ as liver and skeleton combined (Fig. 1). Based on USTUR data, a single compartment

*Corresponding author: leggettrw@ornl.gov 
representing brain was added to the $\mathrm{Pu}$ model, and parameter values for brain were set to yield a long-term total activity ratio Brain / (Liver + Skeleton) of 0.002 .

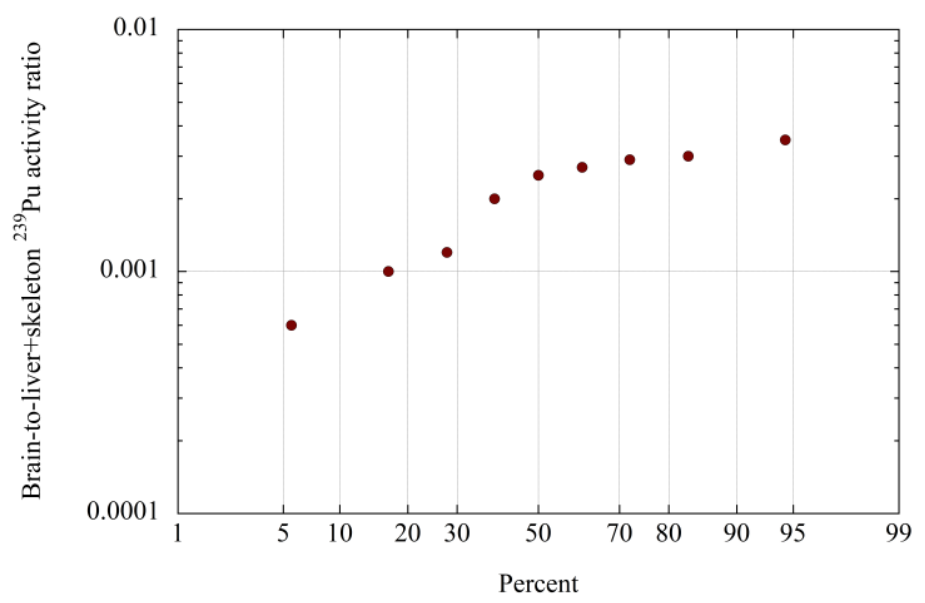

Fig. 1. Brain activity of ${ }^{239} \mathrm{Pu}$ relative to activity in liver plus skeleton.

Table 1 compares dose coefficients for brain for ${ }^{239} \mathrm{Pu}$ and other radionuclides based on alternate versions of the systemic biokinetic model for each radionuclide: Version A which includes brain implicitly in Other tissue and Version B which explicitly depicts a brain pool with kinetics based on brain-specific radiobiological data. Acute input of the radionuclide into blood is assumed. As illustrated in Table 1, results of the study to this point suggest that explicit biokinetic modelling of a brain pool for elements of interest is likely to result in a moderate increase in estimated dose to the brain from most internal emitters.

Table 1. Comparison of dose coefficients $\left(\mathrm{Sv} \mathrm{Bq}^{-1}\right)$ for brain for acute input to blood, based on biokinetic model with brain included in Other tissue and modified version with an explicit brain pool.

\begin{tabular}{lccc}
\hline \multirow{2}{*}{ Nuclide } & \multicolumn{2}{c}{ Version of biokinetic model } & \multirow{2}{*}{ Ratio B:A } \\
\cline { 2 - 3 } & (A) Implicit brain & (B) Explicit brain & \\
\hline${ }^{134} \mathrm{Cs}$ & $5.9 \times 10^{-9}$ & $7.6 \times 10^{-9}$ & 1.3 \\
${ }^{54} \mathrm{Mn}$ & $1.4 \times 10^{-9}$ & $2.4 \times 10^{-9}$ & 1.7 \\
${ }^{203} \mathrm{Hg}$ vapor & $6.4 \times 10^{-10}$ & $9.0 \times 10^{-10}$ & 1.4 \\
${ }^{210} \mathrm{Po}$ & $3.1 \times 10^{-7}$ & $5.4 \times 10^{-7}$ & 1.7 \\
${ }^{239} \mathrm{Pu}$ & $2.2 \times 10^{-5}$ & $2.6 \times 10^{-5}$ & 1.2 \\
\hline
\end{tabular}

\section{References}

1. National Council on Radiation Protection and Measurements. NCRP Commentary No. 25 (2016)

2. J. D. Boice JD Jr. Health Phys 112,392 (2017).

3. J. D. Boice, E. D. Ellis, A. P. Golden, D. J. Girardi, S. S. Cohen, H. Chen, M. T. Mumma, R. E. Shore, R. W. Leggett. Health Phys. 114, 381 (2018).

4. R. W. Leggett, K. F. Eckerman, V. F. Khokhryakov, K. G. Suslova, M. P. Krahenbuhl S. C. Miller. Radiat. Res. 164, 111 (2005).

5. The United States Transuranium and Uranium Registries. www.ustur.wsu.edu 